\title{
Pulmonary Hypertension: Diagnosis and Management
}

\author{
Michael D. McGoon, MD, and Garvan C. Kane, MD, PhD
}

\begin{abstract}
Pulmonary arterial hypertension is a progressive, symptomatic, and ultimately fatal disorder for which substantial advances in treatment have been made during the past decade. Effective management requires timely recognition and accurate diagnosis of the disorder and appropriate selection among therapeutic alternatives. Despite progress in treatment, obstacles remain that impede the achievement of optimal outcomes. The current article provides an overview of the pathobiologic mechanisms of pulmonary arterial hypertension, including genetic substrates and molecular and cellular mechanisms, and describes the clinical manifestations and classification of pulmonary arterial hypertension. The article also reviews established approaches to evaluation and treatment, with emphasis on the appropriate application of calcium channel blockers, prostacyclin analogues, endothelin receptor antagonists, and phosphodiesterase 5 inhibitors. In addition, the authors discuss unresolved issues that may complicate patient management, such as the clinical importance of mild or exercise-related pulmonary arterial hypertension, and they identify avenues by which treatment may advance in the future through the use of combination treatment, outcomes assessment, and exploration of alternative pharmacologic strategies.
\end{abstract}

Mayo Clin Proc. 2009;84(2):191-207

5-HTT = 5-hydroxytryptamine transporter; BMPR2 = bone morphogenetic protein receptor, type II; FDA = Food and Drug Administration; IPAH = idiopathic pulmonary arterial hypertension; mPAP = mean pulmonary arterial pressure; $\mathbf{P A H}=$ pulmonary arterial hypertension; $\mathbf{P A S P}=$ pulmonary arterial systolic pressure; $P C W P=$ pulmonary capillary wedge pressure; $\mathrm{PDE} 5$ = phosphodiesterase 5 ; $\mathrm{PH}=$ pulmonary hypertension; TGF- $\beta=$ transforming growth factor $\beta ;$ WHO $=$ World Health Organization

$\mathrm{T}$ he diagnosis, management, and pathobiologic mechanisms of pulmonary arterial hypertension (PAH) have been of intense interest during the past decade, in large part because of the development of effective treatments that have enhanced the outcome for patients. In the absence of effective treatments, patients with PAH had a median life expectancy of only 2.8 years. Current approaches to the evaluation and management of PAH and to the understanding of the underlying pathophysiologic mechanisms of this condition have been well outlined in recent reviews. ${ }^{1-14}$

This article briefly reviews the generally accepted concepts involved in approaching PAH in the clinical setting. It then addresses problematic issues that remain regarding

From the Pulmonary Hypertension Clinic, Division of Cardiovascular Diseases, Mayo Clinic, Rochester, MN.

Address correspondence to Michael D. McGoon, MD, Division of Cardiovascular Diseases, Mayo Clinic, 200 First St SW, Rochester, MN 55905 (mmcgoon @mayo.edu). Individual reprints of this article and a bound reprint of the entire Symposium on Cardiovascular Diseases will be available for purchase from our Web site www.mayoclinicproceedings.com.

(C) 2009 Mayo Foundation for Medical Education and Research the management of patients with $\mathrm{PAH}$ and identifies possible avenues for advances in treatment.

\section{PATHOBIOLOGIC MECHANISMS OF PULMONARY HYPERTENSION}

\section{Genetics}

In the 1980s, a US registry of patients with primary pulmonary hypertension $(\mathrm{PH})$, currently referred to as idiopathic PAH (IPAH), revealed that $6 \%$ of the patients had first-degree relatives who also had $\mathrm{PAH} .{ }^{15}$ The genetic basis for at least some familial transmission was first recognized in 2000, when allelic variants of the $B M P R 2$ gene, a gene on chromosome 2 that encodes for bone morphogenetic protein receptor, type II (BMPR2) (a transforming growth factor $\beta$ [TGF- $\beta$ ] receptor), were found to be associated with familial PAH. ${ }^{16,17}$ The allelic variants cause amino acid changes in the BMPR2 protein that result in interrupted signal transduction during the process of pulmonary vascular smooth muscle cell apoptosis, thereby promoting cellular proliferation.

As many as $65 \%$ of families with familial PAH have exonic or intronic allelic variants in the BMPR2 gene, which are transmitted in an autosomal dominant manner, and at least $10 \%$ of apparently sporadic cases of IPAH involve isolated exonic allelic variants. ${ }^{18}$ Whether these latter cases represent a spontaneous new allelic variant or occur in families without phenotypic presentation of PAH remains unclear. The penetrance of the allelic variant is low (mean, 20\%; variable among families). ${ }^{19}$ Thus, only 1 in 5 people with a $B M P R 2$ allelic variant exhibit features of $\mathrm{PAH}$, and 1 in 10 offspring of people carrying the variant gene will develop PAH.

Activin-like kinase type 1 is another TGF- $\beta$ receptor, encoded by the ACVRL1 gene on chromosome 12. This receptor is located on endothelial cells. Allelic variants in the ACVRL1 gene have been identified in some families with hereditary hemorrhagic telangiectasia and PAH. ${ }^{20}$ Although ACVRL1 allelic variants are most commonly associated with hereditary hemorrhagic telangiectasia and $\mathrm{PAH}$, allelic variants in another TGF- $\beta$ receptor gene (endoglin $[E N G]$, on chromosome 9) have also been identified in some patients. ${ }^{21}$

5-Hydroxytryptamine transporter (5-HTT) activity is associated with pulmonary arterial smooth muscle cell proliferation. The L-allelic variant of the 5-HTT (also known 


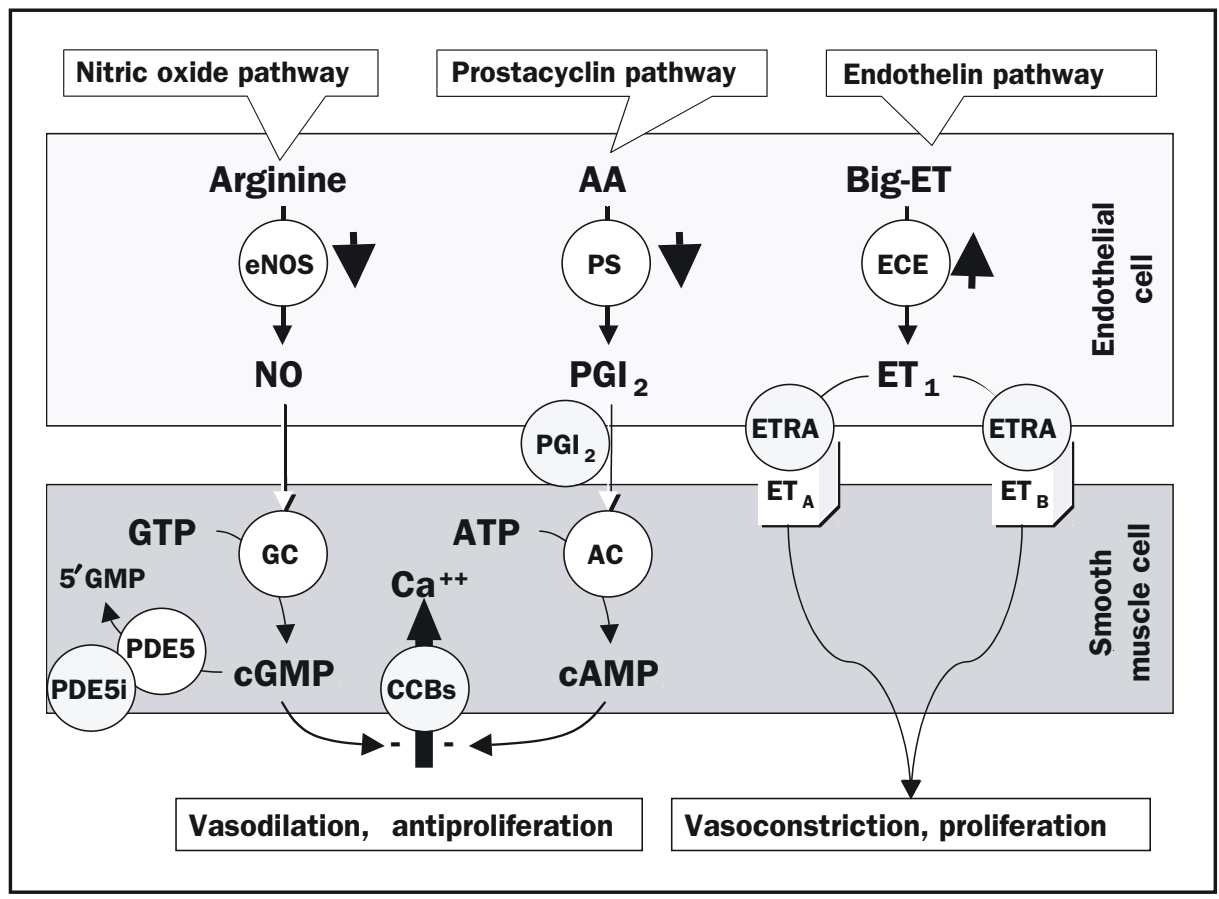

FIGURE 1. The 3 mechanistic pathways known to be disturbed in patients with pulmonary arterial hypertension (PAH). The short, thick, black arrows depict aberrations observed in these pathways in patients with PAH. The points at which drug treatment affects these mechanistic processes are shown in gray circles. AA = arachidonic acid; $\mathrm{CCB}=$ calcium channel blocker; ETRA = endothelin receptor antagonist (eg, bosentan [dual], ambrisentan, and sitaxsentan [receptor A selective]); PDE5i = phosphodiesterase 5 inhibitor (eg, sildenafil).

Left, The nitric oxide (NO) pathway. Nitric oxide is created in endothelial cells by type III (ie, endothelial) NO synthase (eNOS), which in pulmonary arterial smooth muscle cells (PASMCs) induces guanylate cyclase (GC) to convert guanylate triphosphate (GTP) to cyclic guanylate monophosphate (cGMP). Cyclic GMP is a second messenger that constitutively maintains PASMC relaxation and inhibition of PASMC proliferation by ultimately reducing inward flux of calcium ions $\left(\mathrm{Ca}^{++}\right)$. Cyclic GMP is removed by the PDE5 enzyme to yield the inactive product 5 'GMP. Patients with PAH have reduced expression and activity of eNOS.

Middle, The prostacyclin pathway. The production of prostaglandin $\mathrm{I} 2\left(\mathrm{PGI}_{2}[\mathrm{ie}\right.$, prostacyclin]) is catalyzed by prostacyclin synthase (PS) in endothelial cells. In PASMCs, PGI ${ }_{2}$ stimulates adenylate cyclase (AC), thus increasing production of cyclic adenosine monophosphate (CAMP) from adenosine triphosphate (ATP). Cyclic AMP is a second messenger that constitutively maintains PASMC relaxation and inhibition of PASMC proliferation. Patients with PAH have reduced expression and activity of PS.

Right, The endothelin (ET) pathway. Big- (ie, pro-) ET is converted in endothelial cells to $\mathrm{ET}_{1}$ (a 21-amino acid peptide) by endothelin-converting enzyme (ECE). $E T_{1}$ binds to PASMC $E T_{A}$ and $E T_{B}$ receptors, ultimately leading to PASMC contraction, proliferation, and hypertrophy. Endothelin 1 also binds to endothelial cell $\mathrm{ET}_{\mathrm{B}}$ receptors (not illustrated). Patients with PAH have increased expression and activity of ECE.

as SLC6A4) gene promoter, which is associated with increased expression of 5-HTT, ${ }^{22,23}$ was found to be present in homozygous form in $65 \%$ of patients with IPAH, compared with $27 \%$ of controls. ${ }^{24}$

The discovery of genetic allelic variants and polymorphisms that may identify a population at risk of developing PAH raises the possibility of early or preventive management in these patients.

\section{Molecular and Cellular Mechanisms}

Regardless of underlying causes or associations, several interrelated mechanisms play a role in the development and maintenance of PAH (Figure 1). These mechanisms are mediated by 1 or more molecular and cellular processes, including the following: reduced prostacyclin availability caused by diminished endothelial cell prostacyclin synthase activity ${ }^{25}$; elevated endothelin levels resulting from enhanced production and reduced pulmonary clearance ${ }^{26-28}$; decreased nitric oxide synthase expression ${ }^{29,30}$; elevated plasma levels and low platelet 5-hydoxytryptamine lev$\mathrm{els}^{31}$; down-regulation of voltage-gated potassium (eg, Kv1.5) channels of pulmonary vascular smooth muscle cells ${ }^{32,33}$; activity of autoantibodies and proinflammatory cytokines $^{34,35}$; and prothrombotic states arising from endothelial, coagulation, and fibrinolytic cascade and platelet dysfunction. ${ }^{36-39}$

These abnormalities give rise to a predisposition to vasoconstriction over vasodilation of the pulmonary vascu- 
lature, to excess cellular proliferation that outpaces apoptosis, and to a thrombotic diathesis. The dynamic increase in pulmonary vascular resistance appears to be an early substrate of $\mathrm{PAH}$, with subsequent intimal hyperplasia caused by endothelial cell proliferation, medial thickening caused by vascular smooth muscle cell proliferation, development of plexiform lesions caused by disordered endothelial proliferation, and thrombosis in situ that becomes more prominent during the later, clinically apparent stages of the disease.

Appreciation of the underlying mechanisms of $\mathrm{PAH}$ points to the means by which pharmacologic treatment can be used to counteract the mechanisms' consequences.

\section{DIAGNOSIS}

Although pulmonary hypertension refers to the presence of a mean pulmonary arterial pressure (mPAP) of greater than $25 \mathrm{~mm} \mathrm{Hg}$ regardless of mechanism, pulmonary hypertensive disorders are classified into groups on the basis of underlying mechanism, presentation, clinical context, histopathology, and response to treatment (Table 1). ${ }^{40}$ The term pulmonary arterial hypertension pertains to the hemodynamic profile in which high pulmonary pressure is produced by elevation of precapillary pulmonary resistance. Thus, a diagnosis of PAH implies that pulmonary venous pressure, as measured by the pulmonary capillary wedge pressure (PCWP), is normal $(\leq 15 \mathrm{~mm} \mathrm{Hg})$ and that the transpulmonary gradient (ie, the difference between the mPAP and the PCWP) is $10 \mathrm{~mm} \mathrm{Hg}$ or less. The goal of the diagnostic strategy for detection and assessment of PAH is to characterize the hemodynamic profile of $\mathrm{PH}$ and correctly identify the clinical context in which it occurs to appropriately tailor an optimal therapeutic regimen.

If $\mathrm{PH}$ is suspected from the history and physical examination findings of the patient, suitable screening tests are conducted, the presence of $\mathrm{PH}$ is confirmed, and the clinical substrate in which PH occurs is characterized..$^{8,41}$ The generally accepted diagnostic algorithm for $\mathrm{PH}$ is shown in Figure 2. The required diagnostic studies associated with each component of the algorithm are listed in Table 2. Because the hemodynamic profile is pivotal in the assessment, a hemodynamic right heart catheterization is universally considered to be an indispensable part of the examination and should never be omitted. Essential information obtained from the hemodynamic catheterization is shown in Table 2.

\section{GENERAL APPROACH TO THE TREATMENT OF PH}

Of the 6 main lines of treatment used for patients with $\mathrm{PH}$, the first is prevention. Because some forms of $\mathrm{PH}$ have
TABLE 1. Current Clinical Classification of Pulmonary Hypertension ${ }^{\mathrm{a}}$

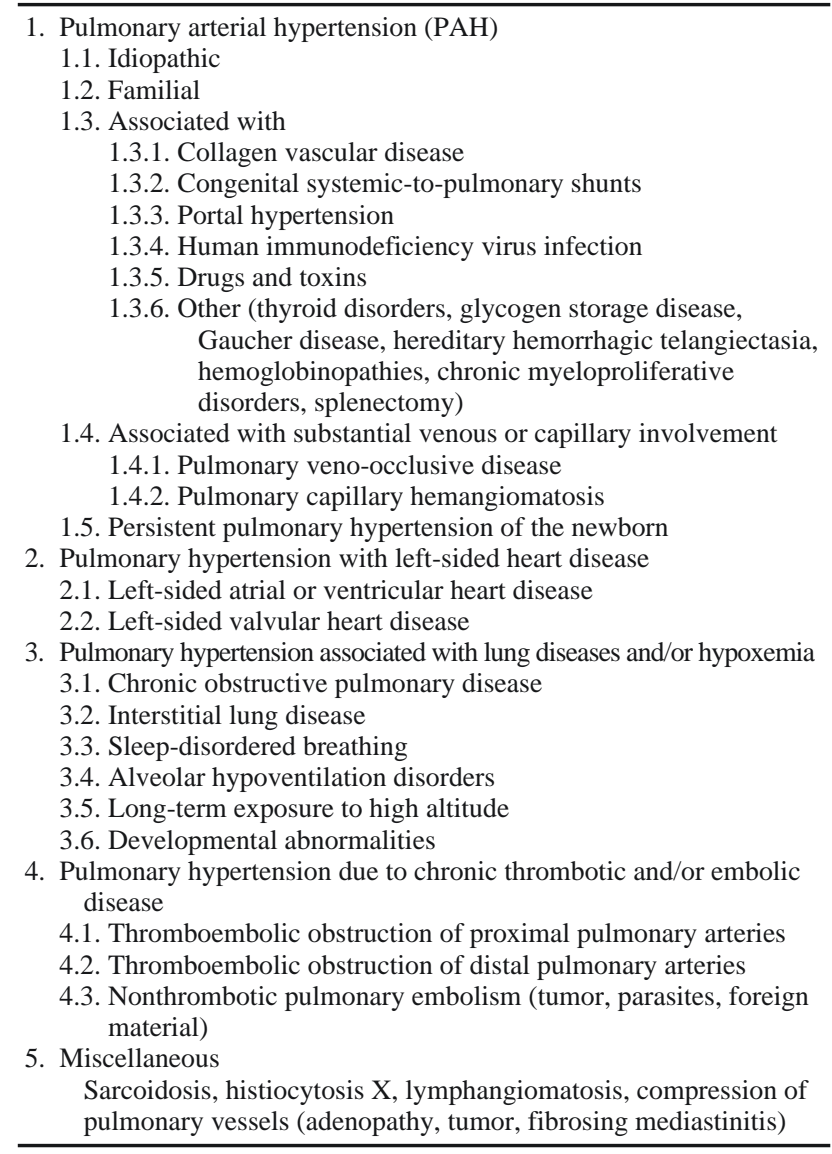

${ }^{a}$ According to Third World Symposium on Pulmonary Arterial Hypertension, 2003.

Adapted from $J$ Am Coll Cardiol, ${ }^{40}$ with permission from Elsevier.

clear causal mechanisms, these risk factors should be eliminated to prevent the development of PH. Repair of congenital left-to-right shunt lesions before the evolution to Eisenmenger syndrome is a notable preventive strategy. Efforts to increase societal awareness of, and curtail the use of, the illicit use of methamphetamine and its derivatives (eg, fenfluramine appetite suppressants ${ }^{42-44}$ ) are likely to reduce the future prevalence of toxic $\mathrm{PAH} .{ }^{45}$

The second line of treatment is appropriate screening of high-risk patients for early signs of PH, usually with carefully performed Doppler echocardiography. High-risk patients include those who have a family history of PAH, known genetic allelic variants associated with $\mathrm{PAH}$, connective tissue diseases (especially limited systemic sclerosis), and congenital heart disease. Patients with symptoms of exertional dyspnea, angina, or syncope should be screened for PH if other causes of the symptoms cannot be identified.

The third line of treatment is to optimize therapy for any associated or causal diseases. Disease of the left side of the 


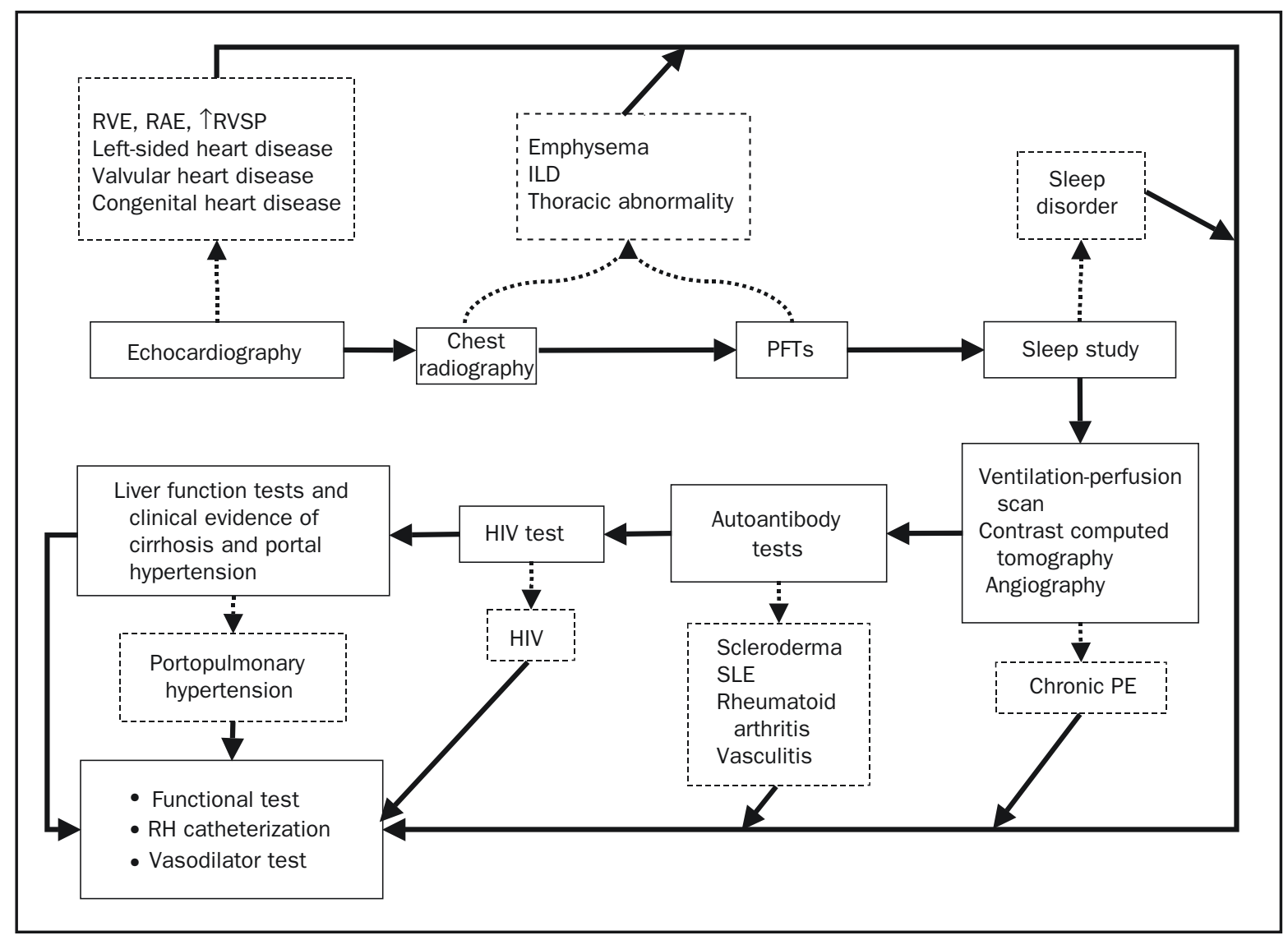

FIGURE 2. Schematic flowchart for evaluation of suspected pulmonary hypertension. The solid arrows indicate progression of tests for evaluation of pulmonary hypertension. The course of evaluation may vary depending on specific results of tests; eg, right heart catheterization may be performed directly after echocardiography. Echocardiographic findings need to be clarified or confirmed before proceeding to evaluation of potential underlying causes of pulmonary hypertension. The dotted arrows point to some potential substrates or characteristics of pulmonary hypertension that may be elucidated by the associated test. The diagnoses shown are not all inclusive. HIV = human immunodeficiency virus; ILD = interstitial lung disease; $\mathrm{PE}=$ pulmonary embolism; PFT = pulmonary function test; RAE = right atrial enlargement; $\mathrm{RH}=$ right heart; RVE = right ventricular enlargement; RVSP = right ventricular systolic pressure; SLE = systemic lupus erythematosus. Adapted from Circulation. ${ }^{5}$

heart and its consequences (eg, blood volume expansion) that can cause increased pulmonary venous pressure should be maximally managed. Sleep disorders must be investigated and appropriately addressed. Hypoxemia of any cause requires correction because of its vasoconstrictive stimulus. Patients with airways disease warrant treatment with bronchodilators, as well as early treatment for infection. In patients with chronic pulmonary thromboembolisms, which may be a manifestation of a possible procoagulant condition, treatment with anticoagulation and, in some cases, inferior vena cava filters is required to reduce the chance of clot recurrence or progression.

The fourth line of treatment is adjunctive, or supportive, therapy, which is directed to the consequences of $\mathrm{PH}$. Death related to PAH is frequently the result of right ventricular failure or arrhythmias likely related to high right ventricular wall stress. Right ventricular decompensation can also lead to peripheral edema, ascites, hepatic congestion, and intestinal edema. After right ventricular failure occurs, aggressive management is required. Sodium and fluid restriction are mandatory parts of this management. Use of loop diuretics, supplemented by metolazone, and potassium-sparing agents are necessary in many patients. However, these medications must be used judiciously to balance reduced intravascular volume and control of edema and ascites with adequate preload of the ventricles to maintain systemic arterial pressure and cardiac output.

Digoxin may be useful for inotropic support in some patients; however, its efficacy in cases of PH is unproven. Cases of advanced right ventricular decompensation may require inpatient management with intravenous inotropic support using dobutamine or milrinone.

Supplemental oxygen throughout the day, nocturnal positive pressure breathing, or both should be used to as- 
TABLE 2. Diagnostic Evaluation in Cases of Suspected $\mathbf{P H}^{\mathbf{a}}$

\begin{tabular}{|c|c|}
\hline Required studies & Pertinent findings \\
\hline Physical examination & $\begin{array}{l}\text { Signs of PH: accentuated } \mathrm{P}_{2} \text {, early systolic click, midsystolic ejection murmur, left parasternal lift, } \mathrm{RV} \mathrm{S}_{4} \text {, } \\
\text { increased jugular "a" wave } \\
\text { Signs of severe PH and/or RV failure: holosystolic murmur that increases with inspiration, increased jugular "v" } \\
\text { waves, pulsatile liver, diastolic murmur, hepatojugular reflux, RV } \mathrm{S}_{3} \text {, marked jugular venous distension, } \\
\text { hepatomegaly, edema, ascites, hypotension }\end{array}$ \\
\hline Chest radiography & $\begin{array}{l}\text { Prominent central pulmonary arteries } \\
\text { RVE } \\
\text { Peripherally attenuated vascular markings }\end{array}$ \\
\hline Electrocardiography & $\begin{array}{l}\text { RV hypertrophy and strain } \\
\text { Right axis deviation } \\
\text { Right atrial enlargement }\end{array}$ \\
\hline Echocardiography & $\begin{array}{l}\text { TRV (RV systolic pressure) } \\
\downarrow \text { AcT }<100 \text { ms or } \uparrow \text { pulmonary regurgitant velocity ( } \uparrow \text { mean pulmonary arterial pressure) } \\
\uparrow \text { TRV at time of pulmonary valve opening ( } \uparrow \mathrm{RV} \text { diastolic pressure) } \\
\uparrow \text { Ratio of TRV to RV outflow tract time-velocity integral or } \uparrow[\mathrm{PEP} / \mathrm{AcT}] / \mathrm{TT} \text { ( } \uparrow \text { pulmonary vascular resistance) } \\
\text { Notching or cessation of RV outflow tract flow in mid-systole ( } \uparrow \text { pulmonary vascular resistance) } \\
\uparrow \text { Severity of tricuspid regurgitation (RVE and altered geometry resulting in apically displaced tethered leaflets) } \\
\text { Coronary sinus dilation ( } \uparrow \text { right atrial pressure) } \\
\text { IVC (with or without hepatic vein) dilation with reduced or absent collapse on inspiration ( } \uparrow \text { right atrial pressure) } \\
\text { RV hypertrophy and dilation, right atrial enlargement, straightened interventricular septum, } \downarrow \text { deceleration time of } \\
\text { early diastolic transmitral flow (RV pressure overload) } \\
\uparrow \text { RV index of myocardial performance (Tei index) (RV dysfunction, } \downarrow \text { ejection time, } \uparrow \text { isovolumic intervals; } \\
\text { correlates with survival) } \\
\text { Pericardial effusion (association with right-sided heart failure, } \downarrow \text { exercise tolerance, and poor } 1 \text {-year survival) } \\
\text { Left heart valvular or (systolic or diastolic) myocardial disease, shunt (causal or contributory cardiac disease) }\end{array}$ \\
\hline Pulmonary function testing & $\begin{array}{l}\text { Obstructive or restrictive lung disease } \\
\text { Diffusing capacity }\end{array}$ \\
\hline Ventilation-perfusion lung scan & Rule out vascular obstruction (chronic thromboembolic $\mathrm{PH}$ ) \\
\hline Antinuclear antibody assay & Screen for connective tissue disease-associated pulmonary arterial hypertension \\
\hline HIV test & Screen for HIV-associated pulmonary arterial hypertension \\
\hline Liver function test & Screen for liver disease-associated pulmonary arterial hypertension \\
\hline $\begin{array}{l}\text { Brain natriuretic peptide } \\
\text { measurement }\end{array}$ & $\begin{array}{l}\text { Measure of RV failure } \\
\text { Prognostic index }\end{array}$ \\
\hline Overnight oximetry & Screen for sleep disorder, nocturnal hypoxemia \\
\hline 6-minute walk test & $\begin{array}{l}\text { Baseline activity level measurement } \\
\text { Contribute to prognosis estimate }\end{array}$ \\
\hline $\begin{array}{l}\text { Hemodynamic right heart } \\
\text { catheterization with } \\
\text { short-acting vasodilator testing }\end{array}$ & $\begin{array}{l}\text { Oxygen saturations (SVC, IVC, right atrial, RV, pulmonary arterial) (saturation step suggesting left-to-right } \\
\text { shunt, assessment of cardiac output) } \\
\text { Right atrial pressure (indicative of RV filling pressure, TR) RV pressure (RV filling and function) } \\
\text { Pulmonary arterial pressure } \\
\text { PCWP or LVEDP (for determination of transpulmonary gradient and precapillary pulmonary vascular resistance) } \\
\text { Cardiac output (pulmonary blood flow measured by thermodilution and Fick method) } \\
\text { Pulmonary vascular resistance (best single characterization of pulmonary hemodynamic status; requires accurate } \\
\text { measure of pulmonary blood flow and PCWP) } \\
\text { Systemic blood pressure } \\
\text { Heart rate } \\
\text { Response to short-acting vasodilator (likelihood of responding to calcium channel blocker treatment) }\end{array}$ \\
\hline
\end{tabular}

Contingent studies

Purpose or indications for use

Transesophageal echocardiography

Contrast-enhanced chest CT

Further definition of valvular and septal structure

Further anatomic definition of pulmonary arteries if chronic thromboembolic $\mathrm{PH}$ suspected

RV function

Pulmonary angiography

High-resolution chest CT

Further anatomic definition of pulmonary arteries if chronic thromboembolic PH suspected

Assessment of possible interstitial lung disease

Clotting studies, antiphospholipid antibody assay

Assessment of possible coagulopathy in chronic thromboembolic disease

Uric acid and troponin

measurements

Polysomnography

Exercise echocardiography

or right heart catheterization

Genetic counseling and testing

Lung biopsy

Prognostic correlates

If overnight oximetry suggests sleep disorder

Assessment of possible abnormal response when no other explanation for symptoms

If multiple family members affected

Rarely advisable because of risk

${ }^{a}$ AcT = acceleration time; CT = computed tomography; HIV = human immunodeficiency virus; IVC = inferior vena cava; LVEDP = left ventricular enddiastolic pressure; $\mathrm{P}_{2}=$ pulmonary valve closing sound; $\mathrm{PCWP}=$ pulmonary capillary wedge pressure; $\mathrm{PEP}=$ preejection period; $\mathrm{PH}=$ pulmonary hypertension; $\mathrm{RV}=$ right ventricular; $\mathrm{RVE}=\mathrm{RV}$ enlargement; $\mathrm{S}_{3}=$ third heart sound; $\mathrm{S}_{4}=$ fourth heart sound; $\mathrm{SVC}=$ superior vena cava; $\mathrm{TR}=$ tricuspid regurgitation; $\mathrm{TRV}=$ tricuspid regurgitant velocity; $\mathrm{TT}=$ total systolic time. 
sure maximal daily duration of normoxia. Hypoxemia may result from a constellation of factors, including low diffusing capacity, right-to-left shunting (caused by congenital heart disease, patent foramen ovale, ventilation-perfusion mismatching, or frank intrapulmonary shunting), and low cardiac output leading to low mixed venous oxygen saturation. Anemia causes decreased oxygen-carrying capacity, further compromising oxygen transport. Although administration of supplemental oxygen may not completely correct low arterial oxygen saturation in all patients, it can produce sufficient improvement to yield a substantial functional benefit in many individuals and, therefore, it should not be overlooked. Moreover, oxygen is a pulmonary vasodilator and may contribute to reducing pulmonary vascular resistance; however, this effect has not been shown to be of definitive long-term benefit.

Hypoxemic patients should avoid air travel and visits to sites at high altitudes unless near normalization of arterial oxygen saturation can be achieved with supplemental oxygen. However, air travel with oxygen often requires special arrangements with the airlines. Although patients are often encouraged to perform normal daily activities and participate in supervised rehabilitation programs to maintain fitness, attempting aggressive exercise or weight-resistance activities is inadvisable.

Influenza and pneumococcal vaccines should be given to prevent pulmonary infections. Early antibiotic treatment for upper respiratory infections is also warranted. However, vasoconstrictive medications (ie, decongestants) should be avoided.

Anticoagulation with warfarin is advised to manage PAH, as well as chronic pulmonary thromboembolism, on the basis of documented coagulation diathesis and reported survival benefits in patients with these conditions ${ }^{46-48}$ and histopathologic evidence of pulmonary vascular thrombosis in situ. ${ }^{49}$ An international normalized ratio of 2.0 to 2.5 is the goal for patients with IPAH or associated PAH, unless a bleeding risk or other contraindication is apparent.

The fifth line of therapy is vascular-targeted treatment directed at reversing or diminishing vasoconstriction, vascular endothelial cell proliferation, and smooth muscle cell proliferation. If pharmacologic treatment fails, surgical interventions, the sixth line of therapy, should be considered. These last 2 lines of therapy are discussed in more detail in the following sections.

\section{VASCULAR-TARGETED TREATMENT}

No current treatment approach to PAH provides a cure. Rather, treatment goals are to reduce pulmonary vascular resistance, pressure, and symptoms and to increase patient activity and longevity. Four classes of medications are available that act on the predominant recognized pathobiologic pathways (Figure 1). Calcium channel blockers reduce the influx of calcium ions into pulmonary arterial smooth muscle cells, thereby reducing calcium-mediated activity of the contractile mechanism. Prostacyclin analogues supplement deficient levels of prostacyclin caused by underexpression of endothelial prostacyclin synthase. Endothelin receptor antagonists block the effect of endothelin at smooth muscle cell receptors. Phosphodiesterase 5 (PDE5) inhibitors promote the activity of the nitric oxide pathway by reducing conversion of cyclic guanylate monophosphate (a second messenger) to $5^{\prime}$ guanylate monophosphate (an inactive product).

\section{Calcium Channel Blockers}

Before the availability of the current therapeutic agents, patients with pulmonary hypertensive conditions were treated with numerous vasodilator agents, with little demonstrable benefit. A report in 1987 indicated that among patients who exhibited the ability to vasodilate in response to short-acting agents, such as adenosine, the use of calcium channel blockers provided substantial survival benefit. ${ }^{50}$ However, only $17(27 \%)$ of the 64 patients in the study exhibited a vasodilator response.

A subsequent retrospective analysis of 557 patients with IPAH showed that only $13 \%$ of patients displayed vasoreactivity, as defined by a decrease of more than $20 \%$ in both MPAP and pulmonary vascular resistance. ${ }^{51}$ Of the patients displaying vasoreactivity, only about half benefited from treatment with long-term calcium channel blockers. Patients who benefited from these medications tended to have had a more profound short-acting vasodilator response during invasive testing.

The results of these studies ${ }^{50,51}$ suggest that mainly patients who have a decline in mPAP of at least $10 \mathrm{~mm} \mathrm{Hg}$ to an absolute value of no more than $40 \mathrm{~mm} \mathrm{Hg}$ and who maintain or improve their cardiac output during testing should be treated with nifedipine, diltiazem, or amlodipine. Verapamil is contraindicated because of its negatively inotropic effect.

\section{Prostacyclin Analogues}

Prostacyclin, a metabolite of arachidonic acid that is produced in the vascular endothelium, inhibits platelet aggregation and is a potent pulmonary vasodilator. In patients with $\mathrm{PAH}$, a relative deficiency of prostacyclin occurs because of down-regulation of prostacyclin synthase.

Epoprostenol is a potent, short-acting pulmonary vasodilator that was approved by the Food and Drug Administration (FDA) in 1995 for treatment of patients who have IPAH or PAH associated with scleroderma and who are in World Health Organization (WHO) functional class III or 
IV. Epoprostenol is administered by continuous intravenous infusion through an indwelling central line. Unfortunately, epoprostenol therapy is expensive and complicated and poses substantial risk. Patients need to carry a continuous infusion pump and frequently replace the pump's drug supply. Dose-dependent adverse effects are common with epoprostenol use, including flushing, headache, jaw and lower extremity muscular pain, diarrhea, nausea, and rash. Complications of epoprostenol use include line-related infections, catheter-associated venous thrombosis, thrombocytopenia, and ascites.

Patients who take epoprostenol require extensive instruction on aseptic technique and drug preparation and must have available to them an appropriate support network, including knowledgeable friends or family members, staff at the specialty pharmacies where this drug is obtained, and staff at their PH clinics. Most patients with PAH who receive parenteral infusions live many miles from the nearest tertiary care facility. Thus, a well-established mechanism for ensuring continuous availability of the clinic staff is mandatory. Sudden interruption of the epoprostenol infusion may cause rebound severe $\mathrm{PH}$ and death. All patients should be instructed in strategies for avoiding such problems and in actions to take should an emergency occur.

Despite the risks, epoprostenol is an effective therapy with more available clinical evidence than any other medication for patients with PAH. It improves exercise capacity, quality of life, hemodynamics, and survival in patients with IPAH and PAH associated with connective tissue disease. ${ }^{52-55}$ It also has been shown to provide benefit for patients who have PAH associated with congenital heart disease, human immunodeficiency virus infection, and portopulmonary hypertension. ${ }^{56-60}$

Most patients experience optimal benefit from epoprostenol at a dosage of 25 to $40 \mathrm{ng} / \mathrm{kg}$ per minute, after incremental increases over the course of 6 to 12 months from an initial dosage of 2 to $6 \mathrm{ng} / \mathrm{kg}$ per minute. Some patients require doses outside of this spectrum, depending on the level of symptomatic benefit or occurrence of adverse effects, such as flushing, rash, jaw pain, leg discomfort, loose stools, or headache. Excessive dosing can produce fatigue as a result of high-output cardiac failure. ${ }^{61}$ Additional concerns with use of epoprostenol include infection of the central venous catheter and sepsis or sudden cessation of the infusion, causing rebound $\mathrm{PH}$ and possible death. Three-year survival of patients with IPAH treated with epoprostenol is $63 \% .^{53,54}$

Treprostinil is a prostacyclin analogue with a longer half-life (3-4 hours) than epoprostenol and, unlike epoprostenol, it is stable at room temperature. These characteristics allow infusion of treprostinil either intravenously (approved by the FDA in 2004) or via a small subcutaneous catheter (approved by the FDA in 2002) with a continuous pump. Treatment by either route improves the 6-minute walk distance in patients who are in WHO functional class III or IV. ${ }^{62,63}$ Three-year survival of patients with IPAH treated with subcutaneous treprostinil monotherapy has been reported at $71 \%{ }^{64}$ Efficacy of treprostinil administered by the intravenous route may be similar to that of epoprostenol; however, comparative survival data are lacking.

The adverse-effect profile of treprostinil is similar to that of epoprostenol. Frequent, severe pain at the site of infusion may limit the dose of treprostinil that can be administered subcutaneously. This limitation may reduce treprostinil's efficacy because the drug's effect on 6-minute walk distance has been shown to be dose dependent.

Investigational trials of inhaled and oral formulations of treprostinil are ongoing. Most patients originally treated with epoprostenol can be switched to intravenous treprostinil with maintenance of 6-minute walk distance, although a larger dose of treprostinil is required ${ }^{65}$ Studies of inhaled and oral administration of treprostinil are also under way.

Iloprost is an inhaled prostacyclin analogue that was approved by the FDA in 2004. It has been shown to improve exercise capacity and hemodynamics in patients with PAH. In a randomized, placebo-controlled, 12-week study, iloprost produced a placebo-corrected increase in 6-minute walk distance of $36 \mathrm{~m}$ in 207 patients with symptomatic IPAH, PAH associated with connective tissue disease or appetite suppressants, or $\mathrm{PH}$ related to inoperable chronic thromboembolic disease ${ }^{66}$ Long-term maintenance of improved exercise capacity and hemodynamics has been observed with iloprost use. ${ }^{67}$ In theory, the use of an inhaled vasodilator could improve ventilation-perfusion matching.

Adverse effects of iloprost use include flushing, headache, and cough. The short duration of action of iloprost may impede its overall efficacy and necessitate frequent 10-minute inhalations, 6 to 9 times per day.

\section{Endothelin Receptor Antagonists}

Endothelin-1 causes vasoconstriction of pulmonary vessels and stimulates smooth muscle and fibroblast proliferation by acting at endothelin receptor subtypes $\mathrm{A}$ and $\mathrm{B}$. In patients with $\mathrm{PAH}$, endothelin-1 levels are increased and correlate with disease severity.

Bosentan is an orally active dual endothelin receptor antagonist that improves exercise capacity, quality of life, hemodynamics, and time to clinical worsening in patients with PAH. ${ }^{68,69}$ Two-year survival of patients with IPAH in whom bosentan was used as first-line therapy is $87 \%$ to $89 \% .^{70,71}$ Bosentan was approved by the FDA in 2001 for treatment of patients with PAH who are in WHO functional 
class III or IV. Adverse effects of bosentan include flushing, edema, nasal congestion, teratogenicity, and mild anemia, as well as a dose-dependent elevation of transaminases in about $10 \%$ of patients. Liver function tests need to be performed monthly on patients taking bosentan. Bosentan displays drug-to-drug interactions with glyburide, cyclosporine, estrogen-based oral contraceptives, and sildenafil.

Ambrisentan is an endothelin receptor antagonist with relative selectivity for the endothelin receptor subtype A. Ambrisentan, which was approved by the FDA in 2007 for use in patients with PAH, appears to improve symptoms, exercise capacity, and hemodynamics. ${ }^{72}$ However, it also predisposes patients to flushing, edema, nasal congestion, and teratogenicity. Although ambrisentan appears to result in a greatly reduced incidence of hepatic enzyme elevations, monthly liver function testing is required in patients taking this medication. ${ }^{73}$

\section{Phosphodiesterase-5 InhiBitors}

Sildenafil, which was originally used for treatment of patients with erectile dysfunction, is a potent, highly specific inhibitor of PDE5 that improves symptoms and functional capacity in patients with PAH. ${ }^{74}$ The FDA approved sildenafil as a treatment for patients with PAH in 2005. Adverse effects associated with sildenafil include headache, flushing, dyspepsia, nasal congestion, and epistaxis. Nitrates must be avoided in patients taking PDE5 inhibitors because the additive effects of the drugs may cause severe systemic hypotension.

Studies of PDE5 inhibitors other than sildenafil (eg, tadalafil) in patients with PAH are under way. In addition, an evaluation is ongoing of the potential benefits of sildenafil in patients who have heart failure with normal ejection fraction, both with and without associated $\mathrm{PH}$.

\section{PHARMACOLOGIC TREATMENT GUIDELINES}

With an increasing number of pharmacologic treatment options available, the decision regarding when and how to use such treatment has taken on added complexity and importance. Although head-to-head comparative trials of available medications are not available, most experienced investigators and clinicians agree that patients with more advanced PAH should be treated initially with parenteral prostacyclin analogues, especially in the setting of right ventricular failure.

Figure 3 depicts an algorithm for the pharmacologic management of PAH on the basis of assessment of disease severity. ${ }^{5}$ In this scenario, PDE5 inhibitors or endothelin receptor antagonists are reasonable initial therapies for patients who have mild to moderate PAH (ie, WHO functional class II or III) or for patients who are not candidates for more invasive therapies. Conversely, intravenous therapies with a prostacyclin analogue should be considered as first-line therapy for patients with severe symptoms (WHO functional class IV) or for patients whose disease progresses on less invasive therapy.

Use of inhaled iloprost and subcutaneously administered treprostinil allows for the administration of an effective prostacyclin analogue without some of the risks associated with continuous intravenous infusion. However, when inhaled or delivered subcutanenously, these agents appear to be less efficacious than when delivered via the parenteral route and may not be well tolerated by the patient.

\section{SURGICAL INTERVENTIONS}

Failure of pharmacologic treatment in patients with $\mathrm{PAH}$ should lead to consideration of possible surgical intervention (ie, lung transplant or balloon atrial septostomy). Patients should be evaluated for transplant candidacy at the time of initiation of an intravenous prostacyclin analogue. This early evaluation is important because of the expected lengthy waiting period for a donor organ to become available after the patient is listed as a transplant candidate.

Patients with advanced right ventricular failure who have not benefited from pharmacologic treatment and who have arterial oxygen saturations within an acceptable range should be considered for percutaneous balloon atrial septostomy. ${ }^{75,76}$

\section{ISSUES IN CURRENT MANAGEMENT}

Despite the availability of recognized diagnostic strategies, clinical circumstances frequently occur in which standard recommendations do not provide unambiguous guidance. The absence of clearly defined evidence-based data does not circumvent the need for devising decisions for the management of patients requiring immediate care.

\footnotetext{
Angina

The predominant symptom of $\mathrm{PAH}$, and the one with which patients typically present, is dyspnea on exertion. However, approximately one-third of patients experience angina during the course of the disease. Angina may develop as a result of any of the following conditions: (1) progressive right ventricular stress causing increased myocardial oxygen demand; (2) critically elevated right ventricular systolic pressure reducing the pressure gradient from the epicardial right coronary artery to the subendocardium, thus reducing coronary flow; (3) development of concomitant atherosclerotic coronary artery disease; or (4) compression of the left main coronary artery by the dilated main pulmonary artery. ${ }^{77-81}$
} 


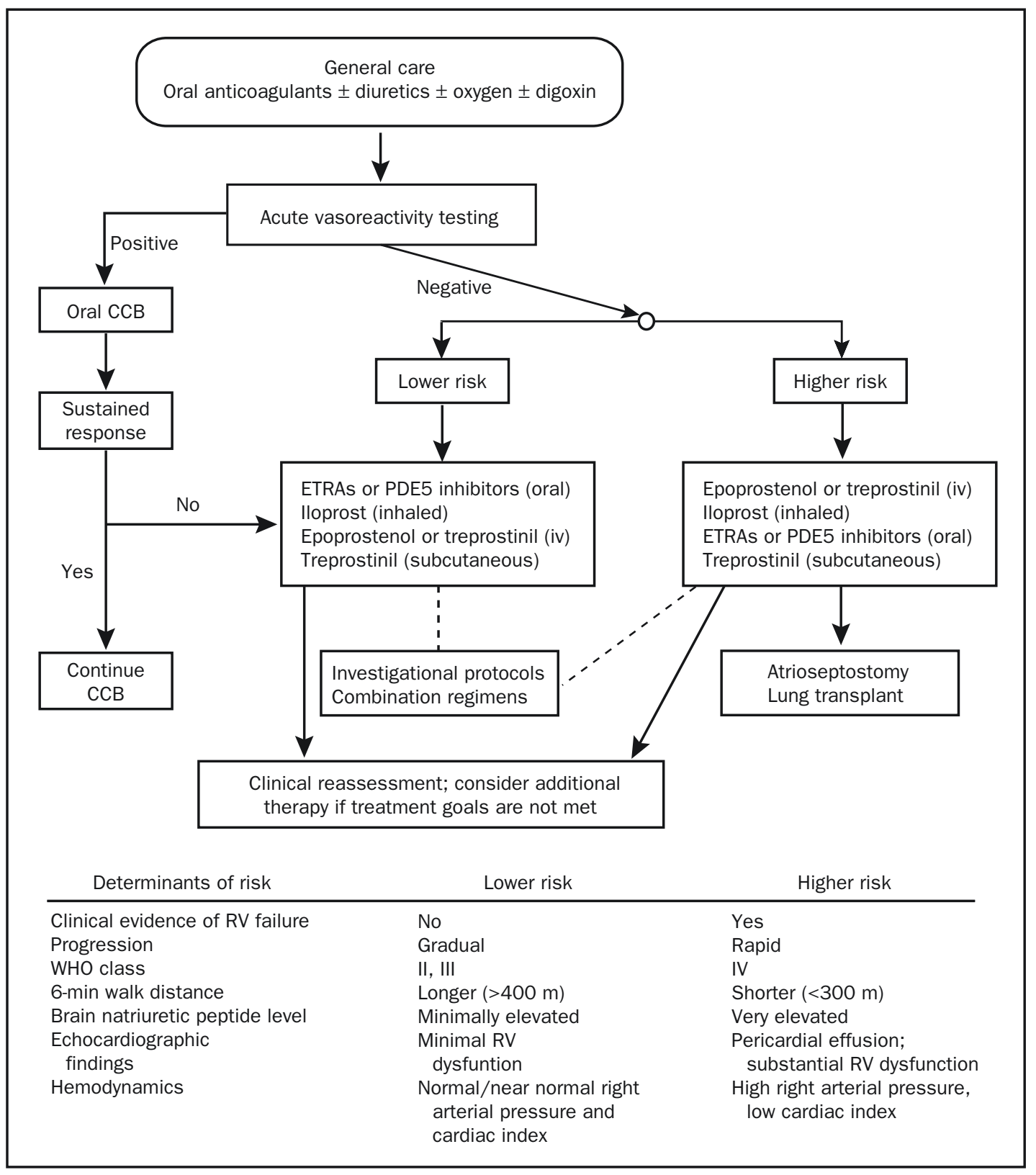

FIGURE 3. Algorithm for the pharmacologic management of pulmonary arterial hypertension. Assessment of risk for each patient includes clinical variables as outlined in the table below the algorithm. Patients deemed to be at highest risk on the basis of clinical assessment should be considered for early intravenous (iv) therapy. Those at lower risk are candidates for oral therapy. Patients should be followed up closely, and their response to therapy should be assessed within several months. If treatment goals are not met, addition of a second agent may be warranted. $\mathrm{CCB}=$ calcium channel blocker; ETRA = endothelin receptor antagonist; PDE5 = phosphodiesterase 5; RV = right ventricular; $\mathrm{WHO}=$ World Health Organization. Adapted from Circulation. ${ }^{5}$

Each of these conditions requires consideration, especially those in which direct intervention may reduce symptoms or avoid fatal complications. Percutaneous coronary intervention has been successfully performed in cases of compression of the left main coronary artery. ${ }^{82}$

\section{SYNCOPE}

Like angina, syncope occurs in approximately $30 \%$ of patients with PAH. It is more prevalent among children than adults. The diagnosis of syncope places a patient in WHO functional class IV, reflecting its prognostically ominous implications. Syncope can be the consequence of arrhyth- 
mias (including atrial arrhythmias that in the absence of PAH would be less symptomatic), systemic vasodilation, ${ }^{83}$ or extreme transient elevation of pulmonary arterial pressure, which may occur with higher levels of exertion.

\section{Clinical Importance of Mild PH}

Of what clinical importance is the presence of borderline or mild PH? Although dyspnea or fatigue may suggest that $\mathrm{PH}$ is the cause, such symptoms are nonspecific. Conversely, atypical symptoms may signal that either the pulmonary arterial pressure measurement is erroneous or, if accurate, does not explain the symptoms. In either case, the symptoms require further evaluation. Dyspnea in an older man with cardiac risk factors is more likely to be an anginal equivalent caused by coronary artery disease than to be related to an incidental echocardiographic estimate of right ventricular systolic pressure mildly above normal.

The defining value for $\mathrm{PH}$ (a pulmonary arterial systolic pressure [PASP] greater than $35 \mathrm{~mm} \mathrm{Hg}$ ) is based on a population average and expert consensus. Unlike systemic hypertension measures, pulmonary measures have not been evaluated with long-term outcome studies to determine which values in otherwise asymptomatic patients lead to worse outcomes. Furthermore, older and obese individuals tend to have higher estimated PASPs on echocardiographic assessment, ${ }^{84}$ making the clinical importance of PASPs unclear.

When even mild PH is suspected, corroborating evidence should be sought via physical examination, chest radiography (prominent hilar vessels), electrocardiography (right axis deviation or right ventricular hypertrophy), and echocardiography (right-sided cardiac chamber enlargement or right ventricular dysfunction). However, the absence of such evidence does not exclude the possibility of mild or early pulmonary vascular disease.

For symptomatic patients in whom no explanation for PH can be determined, further exploration to identify a cause of PH is warranted, and verification and characterization of symptoms with right heart catheterization are required. Combining right heart catheterization with exercise is advisable if resting pulmonary arterial pressures are near normal.

If a finding of mild $\mathrm{PH}$ is made in a low-risk patient without symptoms, a more conservative approach is appropriate, including repeating a focused echocardiographic study in 3 months. If at that time PH is again suggested, a search for a treatable underlying cause is warranted. However, even if mild asymptomatic, minimally symptomatic, or atypically symptomatic PH is confirmed by right heart catheterization, none of the currently available therapies has been shown to produce a favorable risk-to-benefit or cost-to-benefit outcome in patients.

\section{EXERCISE}

The clinical importance of PH that develops only with exercise remains enigmatic. Excessive increases in pulmonary arterial resistance and pressure during exertion could likely account for activity limitations in individuals who have normal pulmonary arterial pressures and are asymptomatic at rest. It is unclear if an exaggerated hemodynamic response to exercise, whether associated with symptoms or not, represents an early warning of more persistent and severe $\mathrm{PH}$ in the future.

Part of the dilemma in understanding the clinical importance of PH with exercise is that a clear delineation between a normal and abnormal response to exertion has not been established for individuals with PH. Nevertheless, when an obviously high pulmonary pressure occurs during activity, this response can be considered pathologic, representing an inability of the normally high-capacity pulmonary vascular bed to accommodate increased pulmonary blood flow. Traditionally, a mPAP of greater than $30 \mathrm{~mm}$ $\mathrm{Hg}$ with exertion has been considered consistent with a definition of $\mathrm{PH}$, but this condition could be considered PAH only if the contemporaneously measured PCWP remained normal. In February 2008, however, at the Fourth World Symposium on PAH (the most recent such symposium), a consensus opinion was expressed that too little is known about the mPAP level at which a normal-abnormal delineation could be described. Thus, the definition of $e x$ ercise-induced PAH was deferred.

Although exercise-induced $\mathrm{PH}$ is a nebulous concept, exercise in the form of respiratory and physical training as part of the management of PAH appears to be efficacious. When superimposed on an optimal stable drug regimen, 15 weeks of respiratory and physical training led to an average increase of $111 \mathrm{~m}$ in patients' 6-minute walk distance, in addition to improvements in other measures of exercise tolerance and quality of life. ${ }^{85}$

\section{Accuracy of Hemodynamic Evaluation}

A criterion of therapeutic success is the degree to which an indicator of disease severity changes during treatment. Among clinical trial populations, a salutary drug response has frequently been based on a placebo-corrected improvement in 6-minute walk distance ranging from 16 to $50 \mathrm{~m}$. However, in an individual patient, it is unclear whether an improvement of this magnitude after 3 months of treatment represents a positive outcome. The determination of a positive outcome depends on the following factors: whether the observed change in walk distance exceeds random variations in distance walked during multiple tests, whether the change in walk distance corresponds with changes in other parameters of disease severity, whether the patient perceives the change in walk distance to have functional value, 


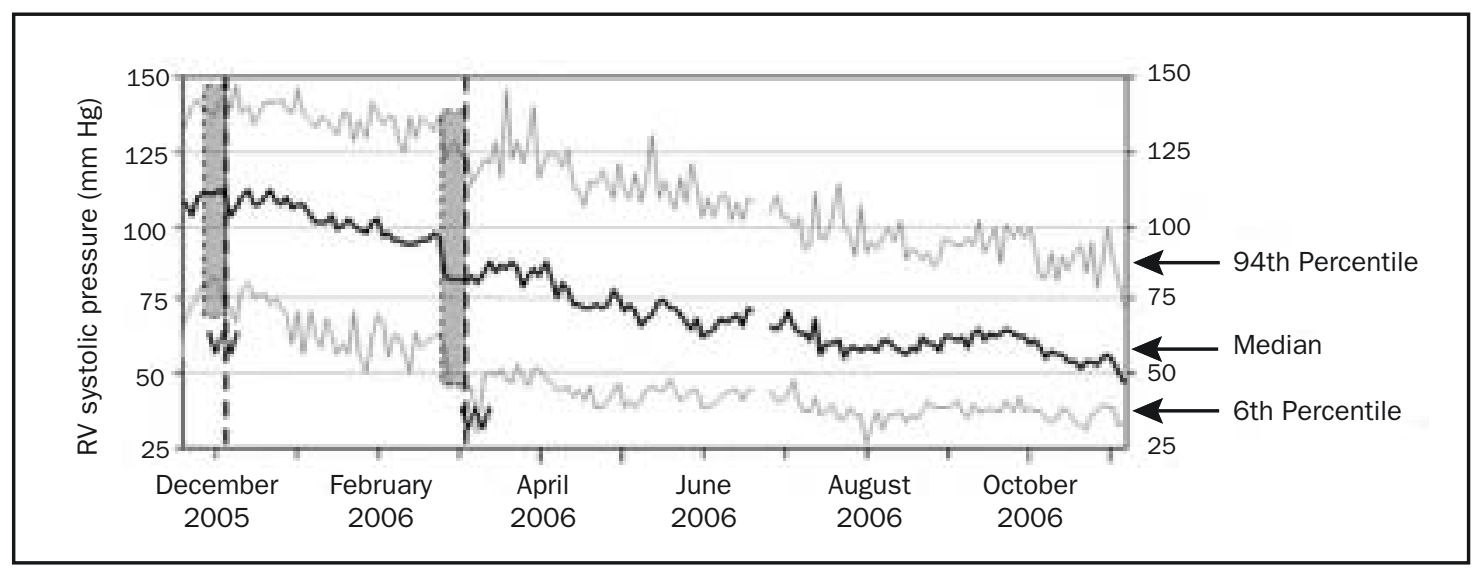

FIGURE 4. Graph of continuous right ventricular (RV) systolic pressure as measured during a 12-month period, showing the trend of daily median values during treatment of a patient with pulmonary arterial hypertension. From $J$ Heart Lung Transplant, ${ }^{88}$ with permission from Elsevier.

whether the change in walk distance proves to be part of a longer-term trend in a consistently positive direction, and whether factors unrelated to disease severity (eg, orthopedic limitations) are having an effect on walk distance. The clinician must recognize all these ambiguities when assessing treatment outcome.

Periodic noninvasive or invasive hemodynamic studies are generally performed as part of the ongoing evaluation of treatment effectiveness in patients with PAH. Although noninvasively estimated PASP correlates closely with simultaneous direct catheter measurements, ${ }^{86}$ the difference between these 2 techniques may be substantial for an individual patient. Thus, the clinician must consider the extent to which differences in Doppler echocardiographic measurements before and after treatment can be reliably attributed to the intervention. A reliable value of PASP determined by Doppler echocardiography requires a suitable tricuspid regurgitant velocity signal and an accurate estimation of right atrial pressure.

As a general rule, a reported value of PASP should be interpreted as having a "confidence range" of plus or minus $5 \mathrm{~mm} \mathrm{Hg}$. Thus, measurements on 2 occasions that differ by no more than $10 \mathrm{~mm} \mathrm{Hg}$ may not represent any actual change. In addition, an estimation of right atrial pressure may affect a diagnosis of PH. Finally, the presence of coexisting pulmonary valve stenosis makes the right ventricular systolic pressure an erroneous measure for estimating PASP, unless the valvular gradient is taken into account.

Although right heart catheterization is considered to be the definitive measurement of pulmonary hemodynamics, it too must be interpreted with some caution. Even during short-term continuous monitoring, catheter-measured pulmonary arterial pressure can vary significantly in the ab- sence of any interventions.$^{87}$ Thus, brief follow-up measurements at intervals of months to years risk superimposing the "noise" of spontaneous variation (as well as the temporary effects of such characteristics as hydration status and anxiety) on changes in the patient caused by progression of disease or response to therapy. Measurement inaccuracy can be further compounded by errors in technique, such as failing to confirm position with a wedged blood saturation (leading to imprecise PCWP), relying on thermodilution cardiac output measurement in the setting of tricuspid regurgitation or intracardiac shunt, and studying the patient during volume expansion or dehydration.

The problems caused by measurement inaccuracies and random sampling during follow-up have led to the concept that continuous ambulatory hemodynamic monitoring of patients may provide more reliable data about trends and responses of pulmonary hemodynamics over time, allowing for more precise predictors of outcome. Figure 4, for example, shows a graph of continuous right ventricular systolic pressure monitoring over a 12-month period, revealing trends in daily median values. ${ }^{88}$ Conclusions about disease progression must incorporate all information about a patient's status, rather than a single set of numbers about hemodynamics, even if the information is obtained invasively. This body of information should include, but not be limited to, symptomatic status, physical examination findings, formal functional assessment, morphologic characteristics, function of the right ventricle, and brain natriuretic peptide levels. The use of this information in treatment is shown in Figure 3.

\section{Disproportionate PH}

Pulmonary hypertension is often associated with other diseases, such as left-sided heart disease, various lung 
diseases, and sleep disorders. In these contexts, $\mathrm{PH}$ is typically mild, and the underlying disease is the determinant of outcome and cause of symptoms. In some cases, however, the severity of PH exceeds what would be expected on the basis of the associated substrate. In these circumstances, $\mathrm{PH}$ may be considered to be out of proportion to the presumed causal mechanism and to be instead a separate phenomenon or an extreme response to the inciting stimulus.

The question arises whether patients in such cases should be considered to have a variant of PAH and should be treated as if they had a predominant vasculopathy. Frequently, such patients are treated with medical regimens targeted to pulmonary vascular conditions; however, no systematically acquired data have been reported supporting the effectiveness of this approach. Although empiric treatment is justifiably considered in such patients with no other clear treatment options, it must be pursued only with great caution and with meticulous follow-up to determine efficacy and absence of clinically important adverse outcomes. Registries and clinical drug studies currently in progress are likely to shed light on some of these problematic populations.

\section{Pregnancy}

Pregnancy poses extremely high risks for the woman with PAH and her fetus. Such women should prevent pregnancy through sterilization or dual-contraceptive methods. Oral contraceptives have been reported to provoke a prothrombotic condition in women with PAH, but these substances have not been unequivocally demonstrated to exacerbate the risks of thrombosis in such women, particularly when anticoagulation is used. ${ }^{89}$

\section{WHICH MEDICATION IS BEST?}

To date, few studies have been published comparing individual medications or classes of medications in the treatment of patients with PAH. The relative efficacy of PAH agents has been determined largely on the basis of clinical experience, indicating that efficacy tends to correlate with the complexity and invasiveness of therapy. Experienced clinicians who treated patients with epoprostenol from 1996 to 2001, when epoprostenol was the only FDA-approved medication for $\mathrm{PAH}$, recall this period as a "golden age" of treatment (Stuart Rich, MD, oral communication). Despite the complexity of therapy, the adverse effects and potential risk, and the expense of epoprostenol, this medication was linked consistently to substantial improvements, both subjective and objective, in symptoms and exercise capacity.

The availability of pharmaceutical alternatives to epoprostenol, particularly oral agents that are less complicated to use for both physicians and patients, has meant that clinicians must carefully consider both efficacy and convenience in selecting a drug. Thus, the choice of medication frequently mandates consideration of the context of treatment and the wishes of the patient. In all cases, however, the patient should be informed of the full spectrum of outcome expectations with the use of any pharmacologic strategy.

\section{Combinations of Medications}

Many patients with PAH do not achieve treatment objectives through monotherapy. Multidrug treatment is appealing because the 3 FDA-approved classes of PAH medications exert their effects by different mechanisms. Thus, 2 or more drugs may produce an augmented effect or may allow for dosing below the levels that cause adverse effects. ${ }^{90}$ Various combinations and sequences of drugs have been investigated in a limited number of studies, and empiric experience is accumulating for use of dual or triple therapy. In the Combination of Bosentan with Epoprostenol in Pulmonary Arterial Hypertension (BREATHE-2) study, ${ }^{91}$ a small trial with 33 patients, 22 of the patients were randomized to begin treatment with epoprostenol plus bosentan, and 11 were randomized to receive epoprostenol and placebo. Statistically nonsignificant trends toward improved hemodynamics were suggested in the epoprostenol-plusbosentan group, but there was no observable effect on functional capacity in this underpowered study. ${ }^{91}$

In the Iloprost Inhalation Solution, Safety and Pilot Efficacy Trial in Combination With Bosentan for Evaluation in Pulmonary Arterial Hypertension (STEP),${ }^{92}$ the addition of iloprost to ongoing therapy with bosentan in 34 patients with PAH resulted in improvements in 6-minute walk distance, functional status, and time to clinical worsening, compared with 33 patients in whom placebo was added to bosentan. This study did not investigate the effect of simply replacing bosentan with iloprost.

In the Pulmonary Arterial Hypertension Combination Study of Epoprostenol and Sildenafil (PACES-1), ${ }^{93} 267$ patients with $\mathrm{PAH}$ who were being treated with a stable epoprostenol dose were randomized to receive either sildenafil or placebo. The patients taking epoprostenol and sildenafil showed a significant improvement in 6-minute walk distance after 16 weeks. Treprostinil Sodium Inhalation Used in the Management of Pulmonary Arterial Hypertension (TRIUMPH-1) $)^{94}$ was a randomized trial in which investigational inhaled treprostinil or placebo was added to either bosentan or sildenafil in 235 patients with PAH. Patients taking bosentan and/or sildenafil plus treprostinil showed significantly more improvement in 6minute walk distance than did those taking bosentan and/or sildenafil plus placebo. Small nonrandomized studies have suggested that sildenafil added to subcutaneous trepros- 
tinil ${ }^{95}$ and sildenafil added to bosentan ${ }^{96}$ may improve exercise tolerance in patients with $\mathrm{PAH}$.

Trials are in progress examining the effects of adding bosentan to sildenafil (COMPASS), tadalafil to bosentan (subset of the Tadalafil in the Treatment of Pulmonary Arterial Hypertension [PHIRST] trial), and iloprost to sildenafil (Ventavis Inhalation With Sildenafil to Improve and Optimize Pulmonary Arterial Hypertension [VISION]). A placebo-controlled study of the addition of an investigational oral treprostinil to either sildenafil or an endothelin receptor antagonist or both (FREEDOM-C) did not show a significant benefit of the study drug over placebo in the primary end point of 6-minute walk distance. ${ }^{97}$

\section{Assessment of Therapeutic Efficacy}

Because pharmacologic regimens can be revised or supplemented, patients should be carefully monitored to assess whether outcome objectives are being achieved. One study adopted a systematic approach to modifying treatment on the basis of whether prognostically improved end points had been achieved. ${ }^{98}$ The strategy of incrementally aggressive therapy based on prespecified criteria progresses from initial use of bosentan to addition of sildenafil, then addition of inhaled iloprost, and finally to intravenous iloprost and lung transplant. This strategy yielded a better outcome for survival, lung transplant, and need for intravenous prostacyclin analogues than was expected given historical controls and predictive formulae. ${ }^{98}$

The need for systematic reevaluation of patients is a compelling argument for managing these patients in a higher-volume referral center with experienced physician and nursing staffs. ${ }^{94}$

\section{Medication Cost and Insurance Coverage}

A complex and demoralizing aspect of treating patients with $\mathrm{PH}$ is the great expense of the required medications. Annual cost can range from about $\$ 12,000$ for sildenafil to more than $\$ 100,000$ for parenteral prostacyclin analogues. Although PH is relatively rare compared with such diseases as coronary artery disease and chronic heart failure, expenses of this magnitude pose a burden not only for individual patients but also for medical insurers and for society as a whole. Negotiating the medical reimbursement obstacles represents a major part of the management of patients with PH.

Use of sildenafil presents uniquely challenging scenarios for the clinician. Although sildenafil is approved for use at a dosage of $20 \mathrm{mg} 3$ times daily, higher doses not infrequently have more beneficial effects. Nevertheless, health plans may consider these higher doses "off-label" and refuse to cover them. Interestingly, higher doses can be provided at the same cost if sildenafil is prescribed as
Viagra (as much as $100 \mathrm{mg} 3$ times daily), which is approved only for erectile dysfunction, rather than as Revatio, which is approved for use in PAH. Even though the drugs are the same and are manufactured by the same pharmaceutical company (Pfizer, New York, NY), medical coverage agencies, including Medicare, nevertheless generally will not cover Viagra for this purpose.

This insurance policy leads to the awkward situation in which men with erectile dysfunction are at an advantage with respect to medical coverage, compared with the typical young woman with life-threatening PAH. Although this inequality can occasionally be rectified for individual patients, such case-by-case corrections do not mitigate the essential injustice of this policy. Efforts are ongoing to correct this policy.

\section{WHO SHOULD MANAGE PATIENTS WITH PAH?}

Pulmonary arterial hypertension is a complex disease with correspondingly complex treatment. In many ways, the pharmacologic treatment of patients with PAH can be likened to the treatment of patients with cancer using chemotherapeutic agents. Indeed, because PAH may represent a disorder of angiogenesis, some investigators consider it to be a neoplastic process. In general, the management of cancer is orchestrated by teams of specialists in centers of expertise where carefully tailored therapy, follow-up, and clinical research are conducted. The management of PAH should arguably be provided in analogous centers of experience, where dedicated multispecialty nursing staff and clinicians can bring to bear their experience and efficiencies to ensure optimal treatment of patients. Early referral by local physicians of patients with $\mathrm{PAH}$ to $\mathrm{PH}$ centers is crucial to this effort.

\section{FUTURE AVENUES IN UNDERSTANDING PH}

\section{Characterizing PaH in the 21st Century}

The clinical understanding of PAH is imperfect and its recognition and diagnosis are frequently delayed. Treatment of patients with PAH is, at best, palliative, and assessment of outcomes and modification of treatment is an ambiguous process. Large populations of patients with $\mathrm{PH}$ are without resources for management, including patients in developing countries who have PH secondary to schistosomiasis. Efforts are under way to improve the medical approach to each of these issues.

Effective diagnosis requires that both physicians and patients be aware of $\mathrm{PH}$ as a potential explanation for observed symptoms. Substantial resources have been deployed to enhance the understanding of $\mathrm{PH}$. A lynchpin in this effort has been the Pulmonary Hypertension Associa- 
TABLE 3. Potential Therapeutic Strategies for Pulmonary Arterial Hypertension ${ }^{\mathrm{a}}$

\begin{tabular}{|c|c|}
\hline Pulmonary arterial hypertension-related abnormality & Potential therapy under investigation \\
\hline $\begin{array}{l}\text { Increased circulating serotonin levels; decreased platelet levels } \\
5-H T T \text { gene polymorphism }\end{array}$ & Selective serotonin reuptake inhibitors (inhibit 5-HTT) \\
\hline Circulating autoantibodies & Immunosuppressive agents \\
\hline Elevated cytokines (IL-1, IL-6) & Statins \\
\hline \multicolumn{2}{|l|}{ Increased chemokine expression } \\
\hline Increased VEGF activity and receptors & Antiangiogenic or proangiogenic manipulation \\
\hline Kv1.5 channels down-regulated on PASMCs & Potassium channel openers \\
\hline Altered procoagulant and fibrinolytic activity of endothelium & Anticoagulation, antiplatelet agents \\
\hline \multirow[t]{2}{*}{ Decreased expression of eNOS, prostacyclin synthase } & Genetically modified PAECs \\
\hline & Long-acting PDE5 inhibition (tadalafil) \\
\hline Rho-kinase role & Rho-kinase inhibition (fasudil) \\
\hline PDGF involvement & PDGF inhibition (imatinib) \\
\hline Low vasoactive intestinal peptide levels & Intranasal vasoactive intestinal peptide \\
\hline Disordered apoptosis & Carbon monoxide \\
\hline Prostacyclin deficiency & Inhaled and oral treprostinil, oral beraprost \\
\hline
\end{tabular}

tion, a patient-initiated coalition of scientists, clinicians, patients, pharmaceutical companies, and specialty pharmacies that has organized educational programs, research funding, support groups, Web sites, and conferences in an effort to advance our understanding of this disease. During the past decade, $\mathrm{PH}$ has become an increasingly prominent topic at international medical meetings, such as the American Thoracic Society's International Conference and the American College of Chest Physicians' CHEST Conference, as well as the focus of attention at such scientific meetings as the American Thoracic Society's Grover Conference.

As information has been disseminated to general internists, pulmonologists, cardiologists, and rheumatologists, it has become increasingly apparent that, although recognition and diagnosis reside in these first-line disciplines, treatment and follow-up need to be focused in dedicated centers of specialization. Centers with dedicated clinics and experienced personnel are best equipped to efficiently address the complex logistical and clinical problems associated with the long-term care of patients with PAH, which is analogous to the management of patients with life-threatening cancers.

Identifying the best and most clinically appropriate way to conduct follow-up management of patients with PAH remains the focus of considerable effort. To date, parameters of symptomatic status and exercise capacity have been the primary variables of therapeutic efficacy and progression of disease. Hemodynamic assessment, although central to the pathophysiologic understanding and diagnosis of the disease, has shown an uncertain relationship to PAH symptoms and outcome. This uncertainty may in part be the result of inherent ambiguities of noninvasive hemodynamic assessment (eg, echocardiography) and the infrequency of invasive evaluation (eg, hemodynamic right heart catheterization).
Avenues for a more definitive understanding of the hemodynamics of $\mathrm{PH}$ are being explored. Implantable hemodynamic monitors may advance our understanding of the hemodynamic natural history of $\mathrm{PH}$ and the response of patients to treatment. ${ }^{88}$ The integration of right ventricular function and ventriculoarterial relationships is likely to yield a more precise understanding of the relation of hemodynamics to the clinical situation and evolution of $\mathrm{PH} .{ }^{99}$

With the advent of multiple therapeutic options, the treatment strategies that may be optimal for particular subpopulations of patients with PAH are unclear. Such subpopulations include patients with IPAH, associated $\mathrm{PAH}$, or PAH with elevated pulmonary venous pressures. Large-scale database registries are being developed to investigate both the demographics of PAH and the outcomes associated with various combinations of pharmacologic treatment. ${ }^{100,101}$

Convergence of these many investigational efforts may substantially advance our understanding of PAH within the next several years.

\section{Treatment Directed at Other Pathobiologic Mechanisms}

Current treatment is directed at 3 recognized pathobiologic pathways involved in the initiation and maintenance of $\mathrm{PH}$ (Figure 1). However, other mechanisms have been implicated in this condition and may have therapeutic ramifications. Many of these mechanisms are either under consideration for clinical studies or are under active investigation (Table 3).

\section{CONCLUSION}

During the past decade, the clinical concept of PAH has evolved from that of a rare and incurable fatal disease to 
that of a not uncommonly encountered syndrome that is a component of numerous clinical scenarios and that can be managed effectively to reduce symptoms and prolong life. Advances in understanding the mechanisms, clinical presentations, and natural history of PAH, as well as treatments for patients with $\mathrm{PAH}$, continue to evolve. Keys to promoting this progress rely on the prompt recognition and evaluation of suspected PAH cases by physicians and the application of effective treatment and clinical study protocols in dedicated PAH centers.

\section{REFERENCES}

1. Humbert M. Update in pulmonary arterial hypertension 2007. Am J Respir Crit Care Med. 2008;177(6):574-579.

2. Chin KM, Rubin LJ. Pulmonary arterial hypertension [published correction appears in J Am Coll Cardiol. 2008 Jul 8;52(2):169]. J Am Coll Cardiol. 2008;51(16): 1527-1538.

3. Taichman DB, Mandel J. Epidemiology of pulmonary arterial hypertension. Clin Chest Med. 2007;28(1):1-22.

4. Rabinovitch M. Pathobiology of pulmonary hypertension. Annu Rev Pathol. 2007;2:369-399.

5. McLaughlin VV, McGoon MD. Pulmonary arterial hypertension. Circulation. 2006;114(13):1417-1431

6. Newman JH, Fanburg BL, Archer SL, et al. Pulmonary arterial hypertension: future directions: report of a National Heart, Lung and Blood Institute/ Office of Rare Diseases Workshop. Circulation. 2004;109(24):2947-2952.

7. McLaughlin VV, Presberg KW, Doyle RL, et al. Prognosis of pulmonary arterial hypertension: ACCP evidence-based clinical practice guidelines. Chest. 2004;126(1 suppl):78S-92S.

8. McGoon M, Gutterman D, Steen V, et al. Screening, early detection, and diagnosis of pulmonary arterial hypertension: ACCP evidence-based clinical practice guidelines. Chest. 2004;126(suppl 1):14S-34S.

9. Galiè N, Torbicki A, Barst R, et al. Guidelines on diagnosis and treatment of pulmonary arterial hypertension: the Task Force on Diagnosis and Treatment of Pulmonary Arterial Hypertension of the European Society of Cardiology. Eur Heart J. 2004;25(24):2243-2278.

10. Badesch DB, Abman SH, Ahearn GS, et al. Medical therapy for pulmonary arterial hypertension: ACCP evidence-based clinical practice guidelines. Chest. 2004;126(suppl 1):35S-62S.

11. Voelkel NF, Cool C. Pathology of pulmonary hypertension. Cardiol Clin. 2004;22(3):343-351

12. McLoughlin P, Hyvelin JM, Howell K. Pulmonary hypertension [letter]. N Engl J Med. 2005;352(4):418-419.

13. Newman JH. Pulmonary hypertension. Am J Respir Crit Care Med. 2005 Nov;172(9):1072-1077. Epub 2005 Jun 30.

14. Badesch DB, Abman SH, Simonneau G, Rubin LJ, McLaughlin VV. Medical therapy for pulmonary arterial hypertension: updated ACCP evidence-based clinical practice guidelines. Chest. 2007;131(6):1917-1928.

15. Rich S, Dantzker DR, Ayres SM, et al. Primary pulmonary hypertension: a national prospective study. Ann Intern Med. 1987;107(2):216-223.

16. Lane KB, Machado RD, Pauciulo MW, et al; International PPH Consortium. Heterozygous germline mutations in BMPR2, encoding a TGF- $\beta$ receptor, cause familial primary pulmonary hypertension [letter]. Nat Genet. 2000;26(1):81-84

17. Deng Z, Morse JH, Slager SL, et al. Familial primary pulmonary hypertension (gene $P P H 1$ ) is caused by mutations in the bone morphogenetic protein receptor-II gene. Am J Hum Genet. 2000 Sep;67(3):737-744. Epub $2000 \mathrm{Jul} 20$.

18. Newman JH, Trembath RC, Morse JA, et al. Genetic basis of pulmonary arterial hypertension: current understanding and future directions. J Am Coll Cardiol. 2004;43(12, suppl S):33S-39S.

19. Loyd JE, Butler MG, Foroud TM, Conneally PM, Phillips JA III, Newman JH. Genetic anticipation and abnormal gender ratio at birth in familial primary pulmonary hypertension. Am J Respir Crit Care Med. 1995;152(1):9397.

20. Trembath RC, Thomson JR, Machado RD, et al. Clinical and molecular genetic features of pulmonary hypertension in patients with hereditary hemorrhagic telangiectasia. $N$ Engl J Med. 2001;345(5):325-334.

21. Harrison RE, Flanagan JA, Sankelo M, et al. Molecular and functional analysis identifies ALK-1 as the predominant cause of pulmonary hypertension related to hereditary haemorrhagic telangiectasia [published correction appears in J Med Genet. 2004;41(7):576]. J Med Genet. 2003;40(12):865-871.

22. Eddahibi S, Humbert M, Fadel E, et al. Hyperplasia of pulmonary artery smooth muscle cells is causally related to overexpression of the serotonin transporter in primary pulmonary hypertension. Chest. 2002;121(3)(suppl): 97S-98S

23. Marcos E, Fadel E, Sanchez O, et al. Serotonin-induced smooth muscle hyperplasia in various forms of human pulmonary hypertension. Circ Res. 2004 May 14;94(9):1263-1270. Epub 2004 Apr 1.

24. Eddahibi S, Humbert M, Fadel E, et al. Serotonin transporter overexpression is responsible for pulmonary artery smooth muscle hyperplasia in primary pulmonary hypertension. J Clin Invest. 2001;108(8):11411150.

25. Christman BW, McPherson CD, Newman JH, et al. An imbalance between the excretion of thromboxane and prostacyclin metabolites in pulmonary hypertension. N Engl J Med. 1992;327(2):70-75.

26. Cacoub P, Dorent R, Maistre G, et al. Endothelin-1 in primary pulmonary hypertension and the Eisenmenger syndrome. Am J Cardiol. 1993; 71(5):448-450.

27. Langleben D, Dupuis J, Hirsch A, et al. Pulmonary endothelin-1 clearance in human pulmonary arterial hypertension. Chest. 2005;128(6)(suppl): $622 \mathrm{~S}$

28. Giaid A, Yanagisawa M, Langleben D, et al. Expression of endothelin1 in the lungs of patients with pulmonary hypertension. $N$ Engl J Med. 1993; 328(24):1732-1739.

29. Giaid A, Saleh D. Reduced expression of endothelial nitric oxide synthase in the lungs of patients with pulmonary hypertension. $N$ Engl J Med. 1995;333(4):214-221.

30. Demoncheaux EAG, Higenbottam TW, Kiely DG, et al. Decreased whole body endogenous nitric oxide production in patients with primary pulmonary hypertension. $J$ Vasc Res. 2005 Mar-Apr;42(2):133-136. Epub 2005 Jan 21.

31. Hervé P, Launay JM, Scrobohaci ML, et al. Increased plasma serotonin in primary pulmonary hypertension. Am J Med. 1995;99(3):249-254.

32. Yuan JX, Aldinger AM, Juhaszova M, et al. Dysfunctional voltagegated $\mathrm{K}+$ channels in pulmonary artery smooth muscle cells of patients with primary pulmonary hypertension. Circulation. 1998;98(14):1400-1406.

33. Weir EK, Reeve HL, Huang JM, et al. Anorexic agents aminorex, fenfluramine, and dexfenfluramine inhibit potassium current in rat pulmonary vascular smooth muscle and cause pulmonary vasoconstriction. Circulation. 1996;94(9):2216-2220.

34. Dorfmüller P, Perros F, Balabanian K, Humbert M. Inflammation in pulmonary arterial hypertension. Eur Respir J. 2003;22(2):358-363.

35. Tuder RM, Groves BM, Badesch DB, Voelkel NF. Exuberant endothelial cell growth and elements of inflammation are present in plexiform lesions of pulmonary hypertension. Am J Pathol. 1994;144(2):275-285.

36. Altman R, Scazziota A, Rouvier J, et al. Coagulation and fibrinolytic parameters in patients with pulmonary hypertension. Clin Cardiol. 1996; 19(7):549-554

37. Hassell KL. Altered hemostasis in pulmonary hypertension. Blood Coag Fibrinolysis. 1998;9(2):107-117.

38. Hoeper MM, Sosada M, Fabel H. Plasma coagulation profiles in patients with severe primary pulmonary hypertension. Eur Respir J. 1998;12(6):1446-1449.

39. Welsh CH, Hassell KL, Badesch DB, Kressin DC, Marlar RA. Coagulation and fibrinolytic profiles in patients with severe pulmonary hypertension. Chest. 1996;110(3):710-717.

40. Simonneau G, Galiè N, Rubin LJ, et al. Clinical classification of pulmonary hypertension. $J$ Am Coll Cardiol. 2004;43(12, suppl S):5S-12S.

41. Barst RJ, McGoon MD, Torbicki A, et al. Diagnosis and differential assessment of pulmonary arterial hypertension. J Am Coll Cardiol. 2004; 43(12)(suppl S):40S-47S 
42. Weir EK, Obreztchikova M, Hong Z. Fenfluramine: riddle or Rosetta stone [editorial]? Eur Respir J. 2008;31(2):232-235.

43. Souza R, Humbert M, Sztrymf B, et al. Pulmonary arterial hypertension associated with fenfluramine exposure: report of 109 cases [published correction appears in Eur Respir J. 2008;31(4):912]. Eur Respir J. 2008 Feb; 31(2):343-348. Epub 2007 Oct 24.

44. Abenhaim L, Moride Y, Brenot F, et al; International Primary Pulmonary Hypertension Study Group. Appetite-suppressant drugs and the risk of primary pulmonary hypertension. $N$ Engl J Med. 1996;335(9):609-616.

45. Chin KM, Channick RN, Rubin LJ. Is methamphetamine use associated with idiopathic pulmonary arterial hypertension? Chest. 2006;130(6):16571663.

46. Fuster V, Steele PM, Edwards WD, Gersh BJ, McGoon MD, Frye RL Primary pulmonary hypertension: natural history and the importance of thrombosis. Circulation. 1984;70(4):580-587.

47. Rich S, Kaufmann E, Levy PS. The effect of high doses of calciumchannel blockers on survival in primary pulmonary hypertension. $N$ Engl J Med. 1992;327(2):76-81.

48. Johnson SR, Granton JT, Mehta S. Thrombotic arteriopathy and anticoagulation in pulmonary hypertension. Chest. 2006;130(2):545-552.

49. Bjornsson J, Edwards WD. Primary pulmonary hypertension: a histopathologic study of 80 cases. Mayo Clin Proc. 1985;60(1):16-25.

50. Rich $\mathrm{S}$, Brundage $\mathrm{BH}$. High-dose calcium channel-blocking therapy for primary pulmonary hypertension: evidence for long-term reduction in pulmonary arterial pressure and regression of right ventricular hypertrophy. Circulation. 1987;76(1):135-141.

51. Sitbon O, Humbert M, Jaïs $X$, et al. Long-term response to calcium channel blockers in idiopathic pulmonary arterial hypertension. Circulation. 2005 Jun 14;111(23):3105-3111. Epub 2005 Jun 6.

52. Barst RJ, Rubin LJ, Long WA, et al; Primary Pulmonary Hypertension Study Group. A comparison of continuous intravenous epoprostenol (prostacyclin) with conventional therapy for primary pulmonary hypertension. $N$ Engl J Med. 1996;334(5):296-301

53. Sitbon $\mathrm{O}$, Humbert $\mathrm{M}$, Nunes $\mathrm{H}$, et al. Long-term intravenous epoprostenol infusion in primary pulmonary hypertension: prognostic factors and survival. J Am Coll Cardiol. 2002;40(4):780-788.

54. McLaughlin VV, Shillington A, Rich S. Survival in primary pulmonary hypertension: the impact of epoprostenol therapy. Circulation. 2002;106(12): 1477-1482.

55. Badesch DB, Tapson VF, McGoon MD, et al. Continuous intravenous epoprostenol for pulmonary hypertension due to the scleroderma spectrum of disease. Ann Intern Med. 2000;132(6):425-434.

56. Aguilar RV, Farber HW. Epoprostenol (prostacyclin) therapy in HIVassociated pulmonary hypertension. Am J Respir Crit Care Med. 2000;162(5): 1846-1850.

57. Kuhn KP, Byrne DW, Arbogast PG, Doyle TP, Loyd JE, Robbins IM. Outcome in 91 consecutive patients with pulmonary arterial hypertension receiving epoprostenol. Am J Respir Crit Care Med. 2003 Feb 15;167(4):580586. Epub 2002 Nov 21.

58. Kuo PC, Johnson LB, Plotkin JS, Howell CD, Bartlett ST, Rubin LJ. Continuous intravenous infusion of epoprostenol for the treatment of portopulmonary hypertension. Transplantation. 1997;63(4):604-606.

59. McLaughlin VV, Genthner DE, Panella MM, Hess DM, Rich S. Compassionate use of continuous prostacyclin in the management of secondary pulmonary hypertension: a case series. Ann Intern Med. 1999;130(9): 740-743.

60. Rosenzweig EB, Kerstein D, Barst RJ. Long-term prostacyclin for pulmonary hypertension with associated congenital heart defects. Circulation. 1999;99(14):1858-1865.

61. Rich S, McLaughlin VV. The effects of chronic prostacyclin therapy on cardiac output and symptoms in primary pulmonary hypertension. $\mathrm{J} \mathrm{Am} \mathrm{Coll}$ Cardiol. 1999;34(4):1184-1187.

62. Simonneau G, Barst RJ, Galie N, et al; Treprostinil Study Group. Continuous subcutaneous infusion of treprostinil, a prostacyclin analogue, in patients with pulmonary arterial hypertension: a double-blind, randomized, placebo-controlled trial. Am J Respir Crit Care Med. 2002;165(6):800804.

63. Tapson VF, Gomberg-Maitland M, Mclaughlin VV, et al. Safety and efficacy of intravenous treprostinil for pulmonary arterial hypertension: a prospective, multicenter, open-label 12-week trial. Chest. 2006;129(3):683688.

64. Barst RJ, Galie N, Naeije R, et al. Long-term outcome in pulmonary arterial hypertension patients treated with subcutaneous treprostinil. Eur Respir J. 2006;28(6):1195-1203. Epub 2006 Aug 9.

65. Gomberg-Maitland M, Tapson VF, Benza RL, et al. Transition from intravenous epoprostenol to intravenous treprostinil in pulmonary hypertension. Am J Respir Crit Care Med. 2005 Dec 15;172(12):1586-1589. Epub 2005 Sep 8

66. Olschewski H, Simonneau G, Galiè N, et al; Aerosolized Iloprost Randomized Study Group. Inhaled iloprost for severe pulmonary hypertension. N Engl J Med. 2002;347(5):322-329.

67. Hoeper MM, Schwarze M, Ehlerding S, et al. Long-term treatment of primary pulmonary hypertension with aerosolized iloprost, a prostacyclin analogue. N Engl J Med. 2000;342(25):1866-1870.

68. Channick RN, Simonneau G, Sitbon O, et al. Effects of the dual endothelin-receptor antagonist bosentan in patients with pulmonary hypertension: a randomised placebo-controlled study. Lancet. 2001;358(9288:11191123

69. Rubin LJ, Badesch DB, Barst RJ, et al. Bosentan therapy for pulmonary arterial hypertension [published correction appears in N Engl J Med. 2002; 346(16):1258]. N Engl J Med. 2002;346(12):896-903.

70. McLaughlin VV, Sitbon O, Badesch DB, et al. Survival with first-line bosentan in patients with primary pulmonary hypertension [published correction appears in Eur Respir J. 2005;25(5):942]. Eur Respir J. 2005;25(2):244249

71. Provencher S, Sitbon O, Humbert M, Cabrol S, Jaïs X, Simonneau G. Long-term outcome with first-line bosentan therapy in idiopathic pulmonary arterial hypertension. Eur Heart J. 2006;27(5):589-595. Epub 2006 Jan 23.

72. Galiè N, Badesch DB, Oudiz R, et al. Ambrisentan therapy for pulmonary arterial hypertension. J Am Coll Cardiol. 2005;46(3):529-535.

73. McGoon MD, Frost AE, Oudiz RJ, et al. Ambrisentan therapy in patients with pulmonary arterial hypertension who discontinued bosentan or sitaxsentan due to liver function test abnormalities [published online ahead of print September 23, 2008]. Chest. doi:10.1378/chest.08-1028. http://chestjournal.org/cgi /content/abstract/chest.08-1028v1. Accessed December 8, 2008.

74. Galiè N, Ghofrani HA, Torbicki A, et al; Sildenafil Use in Pulmonary Arterial Hypertension (SUPER) Study Group. Sildenafil citrate therapy for pulmonary arterial hypertension [published correction appears in $N$ Engl J Med. 2006;354(22):2400-2401]. N Engl J Med. 2005;353(20):2148-2157.

75. Reichenberger F, Pepke-Zaba J, McNeil K, Parameshwar J, Shapiro LM. Atrial septostomy in the treatment of severe pulmonary arterial hypertension. Thorax. 2003;58(9):797-800.

76. Sandoval J, Gaspar J, Pulido T, et al. Graded balloon dilation atrial septostomy in severe primary pulmonary hypertension. J Am Coll Cardiol. 1998;32(2):297-304

77. Bonderman D, Fleischmann D, Prokop M, Klepetko W, Lang IM. Left main coronary artery compression by the pulmonary trunk in pulmonary hypertension. Circulation. 2002;105(2):265.

78. Dodd JD, Maree A, Palacios I, et al. Left main coronary artery compression syndrome: evaluation with 64-slice cardiac multidetector computed tomography. Circulation. 2007;115(1):e7-e8.

79. Kawut SM, Silvestry FE, Ferrari VA, et al. Extrinsic compression of the left main coronary artery by the pulmonary artery in patients with longstanding pulmonary hypertension. Am J Cardiol. 1999;83(6):984-986.

80. Lindsey JB, Brilakis ES, Banerjee S. Acute coronary syndrome due to extrinsic compression of the left main coronary artery in a patient with severe pulmonary hypertension: successful treatment with percutaneous coronary intervention. Cardiovascr Revasc Med. 2008;9(1):47-51.

81. Mesquita SM, Castro CR, Ikari NM, Oliveira SA, Lopes AA. Likelihood of left main coronary artery compression based on pulmonary trunk diameter in patients with pulmonary hypertension. Am J Med. 2004;116(6): 369-374.

82. Rich S, McLaughlin VV, O'Neill W. Stenting to reverse left ventricular ischemia due to left main coronary artery compression in primary pulmonary hypertension. Chest. 2001;120(4):1412-1415.

83. Mikhail GW, Gibbs JSR, Yacoub MH. Pulmonary and systemic arterial pressure changes during syncope in primary pulmonary hypertension. Circulation. 2001;104(11):1326-1327. 
84. McQuillan BM, Picard MH, Leavitt M, Weymann AE. Clinical correlates and reference intervals for pulmonary artery systolic pressure among echocardiographically normal subjects. Circulation. 2001;104(23):27972802 .

85. Mereles D, Ehlken N, Kreuscher S, et al. Exercise and respiratory training improve exercise capacity and quality of life in patients with severe chronic pulmonary hypertension. Circulation. 2006 Oct;114(14):1482-1489. Epub 2006 Sep 18.

86. Currie PJ, Seward JB, Chan KL, et al. Continuous wave Doppler determination of right ventricular pressure: a simultaneous Doppler-catheterization study in 127 patients. J Am Coll Cardiol. 1985;6(4):750-756.

87. Rich S, D'Alonzo GE, Dantzker DR, Levy PS. Magnitude and implications of spontaneous hemodynamic variability in primary pulmonary hypertension. Am J Cardiol. 1985;55(1):159-163.

88. Frantz RP, Benza RL, Kjellström B, et al. Continuous hemodynamic monitoring in patients with pulmonary arterial hypertension. J Heart Lung Transplant. 2008 Jul;27(7):780-788. Epub 2008 Jun 2.

89. Parambil JG, McGoon MD. Pregnancy and pulmonary hypertension. In: Oakley C, Warnes CA, eds. Heart Disease in Pregnancy. Malden, MA: Blackwell Publishing; 2007:59-78.

90. O'Callaghan DS, Gaine SP. Combination therapy and new types of agents for pulmonary arterial hypertension. Clin Chest Med. 2007;28(1):169185.

91. Humbert M, Barst RJ, Robbins IM, et al. Combination of bosentan with epoprostenol in pulmonary arterial hypertension: BREATHE-2. Eur Respir J. 2004;24(3):353-359

92. McLaughlin VV, Oudiz RJ, Frost A, et al. Randomized study of adding inhaled iloprost to existing bosentan in pulmonary arterial hypertension. Am J Respir Crit Care Med. 2006 Dec;174(11):1257-1263. Epub 2006 Aug 31.
93. Simonneau G, Rubin LJ, Galiè N et al; PACES Study Group. Addition of sildenafil to long-term intravenous epoprostenol therapy in patients with pulmonary arterial hypertension: a randomized trial. Ann Intern Med. 2008; 149(8):521-530.

94. United Therapeutics. TRIUMPH-1 trial of Viveta in pulmonary arterial hypertension meets primary endpoint. November 1, 2007. http://ir.unither.com /releasedetail.cfm?ReleaseID=272478. Accessed January 12, 2009.

95. Gomberg-Maitland M, McLaughlin V, Gulati M, Rich S. Efficacy and safety of sildenafil added to treprostinil in pulmonary hypertension. Am J Cardiol. 2005 Nov 1;96(9):1334-1336. Epub 2005 Sep 16.

96. Hoeper MM, Faulenbach C, Golpon H, Winkler J, Welte T, Niedermeyer J. Combination therapy with bosentan and sildenafil in idiopathic pulmonary arterial hypertension. Eur Respir J. 2004;24(6):1007-1010.

97. Medical News Today. FREEDOM-C trial of oral treprostinil in pulmonary arterial hypertension fails to meed primary endpoint. http://www .medicalnewstoday.com/articles/129702.php. Accessed January 12, 2009.

98. Hoeper MM, Markevych I, Spiekerkoetter E, Welte T, Niedermeyer J. Goal-oriented treatment and combination therapy for pulmonary arterial hypertension. Eur Respir J. 2005;26(5):858-863.

99. Voelkel NF, Quaife RA, Leinwand LA, et al. Right ventricular function and failure: report of a National Heart, Lung, and Blood Institute Working Group on Cellular and Molecular Mechanisms of Right Heart Failure. Circulation. 2006;114(17):1883-1891.

100. McGoon MD, Krichman A, Farber HW, et al. Design of the REVEAL Registry for US patients with pulmonary arterial hypertension. Mayo Clin Proc. 2008;83(8):923-931.

101. Humbert M, Sitbon O, Chaouat A, et al. Pulmonary arterial hypertension in France: results from a national registry. Am J Respir Crit Care Med. 2006 May 1;173(9):1023-1030. Epub 2006 Feb 2.

\section{The Symposium on Cardiovascular Diseases will continue in the March issue.}

